\title{
The study of autobiographical memory and identity processing styles in Afghan immigrant adolescents suffering from post-traumatic stress disorder
}

\author{
1. MSc in Clinical Psychology of Child and Adolescence, Kharazmi University, Tehran, Iran \\ 2. Professor of Clinical Psychology Department, Kharazmi University, Tehran, Iran \\ 3. Assistant Professor of Clinical Psychology Department, Kharazmi University, Tehran, Iran \\ 4. PhD Student in Cognitive Sciences, Institute for Cognitive Science Studies, Tehran, Iran \\ 5. MSc Student in Clinical Psychology, Kharazmi University, Tehran, Iran
}

Fatemeh Sanambari $^{1}$, Alireza Moradi ${ }^{2 *}$ (D), Maryam Moghaddasin ${ }^{3}$, Vida Sadat Mirabolfathi ${ }^{4}$, Mehdi Parouee $^{5}$

Recieved: 20 Jun. 2017

Revised: 5 Dec. 2018

Accepted: 20 Dec. 2018

Keywords

Post-traumatic stress disorder (PTSD)

Autobiographical memory

Identity processing styles

Afghan immigrant adolescents

Corresponding author

Alireza Moradi, Professor of

Clinical Psychology Department,

Kharazmi University, Tehran, Iran

Email: Moradi90@yahoo.com

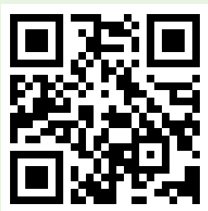

\section{Abstract}

Introduction: This study aims to investigate autobiographical memory and identity styles in Afghan immigrant adolescent with post-traumatic stress disorder.

Methods: There are three groups in this causal-comparative study (18 control subjects, 14 Non-PTSD, and 16 PTSD subjects). Subjects were recruited by using Semi-Structural Interview for PTSD, The Impact of Event Scale-Revised, Beck Anxiety Inventory, Children Depression Scale, Autobiographical Memory Test, and Berzonsky’s Identity Style Inventory To analyze data, one-way covariance and one-way variance analysis were used.

Results: There was a significant difference between autobiographical memory among immigrant adolescents with PTSD, Non-PTSD and control group. Beside, these groups had a significant difference in depression and anxiety levels. But there was no significant relation between identity and autobiographical memory.

Conclusion: The results of this study revealed that performance of Afghan immigrant adolescents with PTSD in special retrieval of autobiographical memory items is weaker than control and Non-PTSD groups. However, the variance analyze have shown that there was no significant difference in terms of identity style among these three groups. Problems in retrieving autobiographical memory information were not related to identifying style in this group of Afghan immigrant adolescents. 
D)

\title{
بررسى حافظه شرح حال و سبكهاى يردازش هويت در نوجوانان مهاجر افغان مبتلا به اختلال استرس يس از سانحه
}

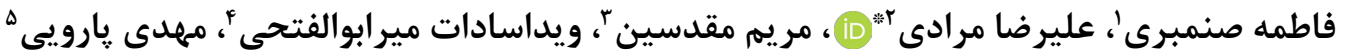

\author{
ا. أ. كارشناسى ارشد روانشناسى بالينى كودك و نوجوان، دانشكاه خوارزمى، تهران، ايران

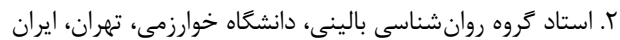

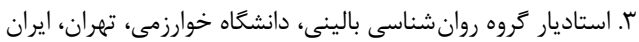

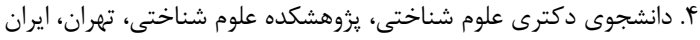

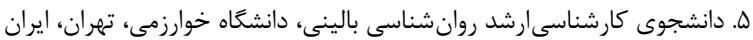

\section{are}

مقدمهه: هدف يزوهش حاضر بررسى حافظه شح حال و سبكهاى يردازش هويت در نوجوانان مهاجر افغان مبتلا به اختلال استرس يس از سانحه بود.

روش كارة اين يروهش از نوع يس رويدادى (على مقايسهاى) بود، كه در آن آزمودنىها كه با روش نمونه كيرى در دسترس در ؟

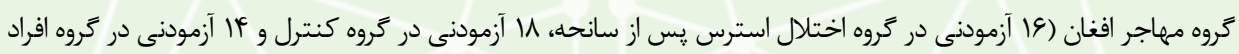

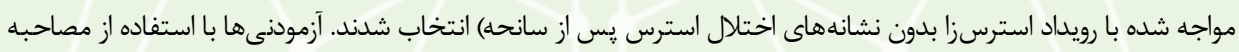
نيمه ساختاريافته براى اختلال استرس يس از سانحه، مقياس تجديد نظر شده تاثير رويداد، مقياس اضطراب Beck، مقياس افسردكى CDS-A، آزمون حافظه شح حال و پرسشنامه هويت Berzonsky مورد ارزيابى قرار كرفتند. براى تحليل دادهها از تحليل واريانس يك طرفه و خند متغيره، تحليل كوواريانس يك طرفه وضريب همبستگى استفاده شد. يافته ها: بين عملكرد بيش كلى كرايى حافظه شح حال نوجوانان مهاجر افغان مبتلا به اختلال استرس یس از سانحه و كروه مواجه شده با رويداد استرسزا بدون نشانه هاى اختلال استرس يس از سانحه و كنترل تفاوت معنادار وجود داشت. همجنين بين گروههاى مورد نظر در سطح اضطراب و افسردىى تفاوت معنادارى وجود داشت. اما ميان حافظه شح حال و هويت رابطه معنادارى بدست نيامد. نتيجه كيرى: يافتههاى اين مطالعه نشان داد كه عملكرد نوجوانان مهاجر افغان مبتلا به اختلال استرس پِ از سانحه در بازيابى اختصاصى حافظه شح حال ضعيفتر از نوجوانان دو گروه ديكر است. همجنين بين كروهها از نظر سبك هويت تفاوت معنادارى نداشت، از طرفى ميان آسيب بازيابى اطلاعات از حافظه شح حال با سبك هويتى نوجوانان مهاجر افغان مبتلا بـ ارتباطى وجود ندارد. بنابراين بر مبناى مطالعات و مشاهدات صورت كرفته در يثوهش به نظر مى رسد كه در اين كروه از نوجوانان مهاجر افغان مبتلا به PTSD متغير حافظه شح حال نقش واسطهاى در تبيين سبكهاى هويتى ندارد.
\end{abstract} دريافت: • • اصلاح نهايى:

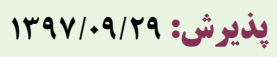
وازههاى كليدى اختلال استرس بعد از سانحه حافظه شرح حال سبك هاى بردازش هويت نوجوانان مهاجر افغان

\section{نويسنده مسئول}

عليرضا مرادى، استاد گروه روانشناسى مئى بالينى، دانشَاه خوارزمى، تهران، ايران ايميل:yoradi90@yahoo.com

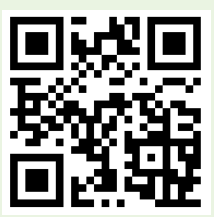

doi doi.org/10.30699/icss.21.4.23

مقدمه

رايجترين اختلال روانى (Post-traumatic stress disorder (PTSD)) بعد از مواجهه با رويداد استرسزا است. جهار نشانه اصلى PTSD كه

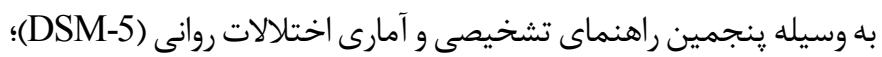
مطرح شده است، عبارتند از: توليد مجدد واقعه آسيبزا به صورت ذهنى، اجتناب مداوم از وقايع مرتبط با آسيب و فراموشى ززينشى رويداد تجربه
كودكان در معرض رويدادهاى آسيبزاى (Traumatic) متنوع قرار دارند و وِاسخ هر كودى به اين وقايع منحصر به فرد است. تعدادى از كود كان بعد از مواجهه با رويداد استرسزا به آسانى از آن عبور مى كنند لند اما تعدادى از آنها واكنش هايى از قبيل افسردگى، اضطراب و ديخر مشكلات رفتارى را نشان مى دهند، اختلال استرس يس از سانحه 
شرح حال، حس هويت فرد را تحت تاثير قرار مى دهد و باعث تغييراتى در

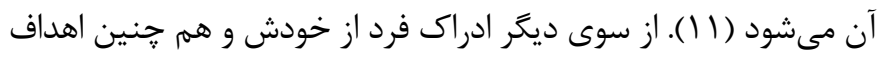

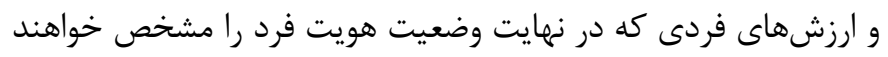

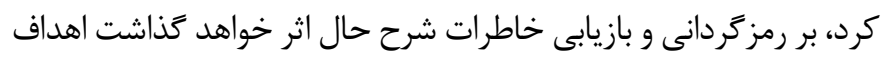

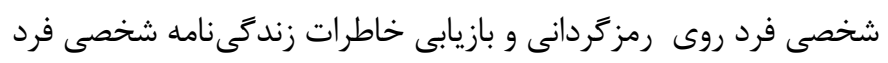

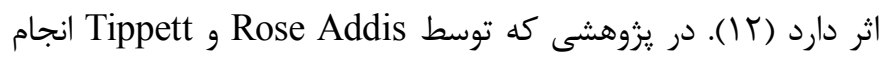

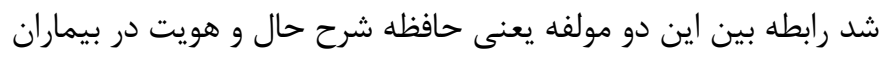

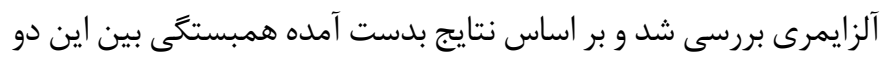

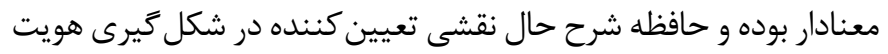
منسجم دارا بود (1) (1). با توجه به اين كه اختلال استرس بعد از سانحه در نعرد

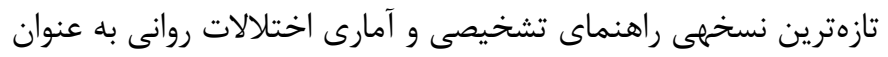
طبقه تشخيصى جداكانه با نشانهاى مرضى مجزا كسترش يافته است،

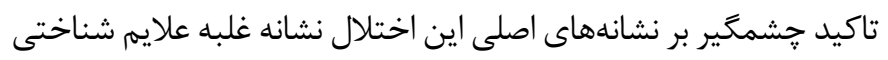

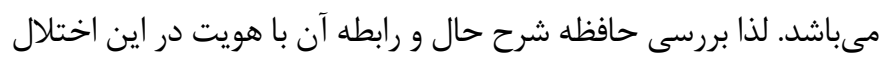

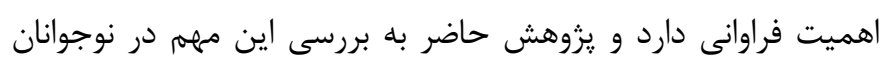

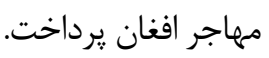

\section{روش كار}

روش يزوهش حاضر ازنوع مطالعات على مقايسهاى بود. جامعهى يزوهش را نوجوانان مهاجر افغان مبتلا به اختلال استرس يس از سانحه در شهر كرج

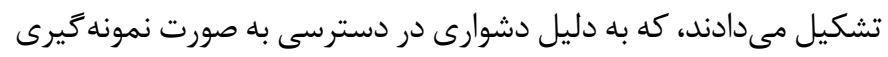

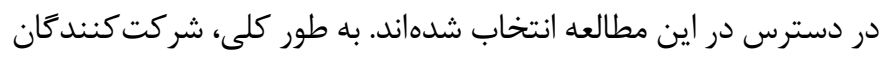

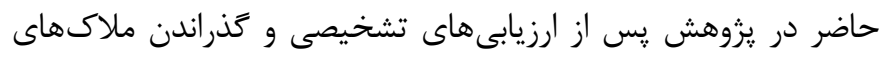

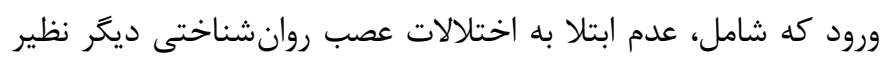

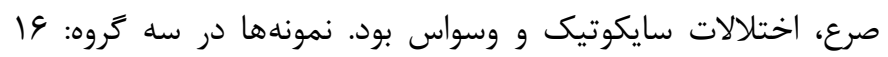

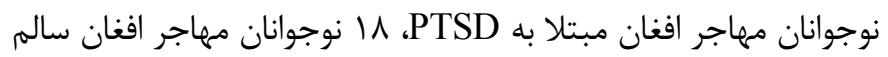
(كنترل)، fl ا نوجوانان مهاجر افغان مواجه شده با تروما بدون نشانهاى

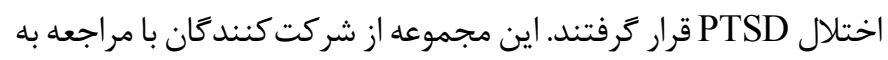
مراكز آموزشى كودكان كار و خيابان كرج (خانههاى مهر) و و پس از از ارائه توضيحى مختصر در مورد اهداف يزوهش و سيس مصاحبه تشخيصى نيمه

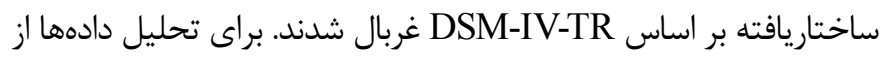

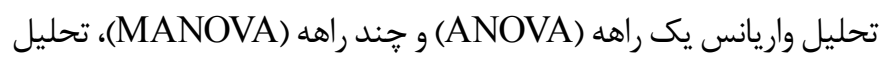

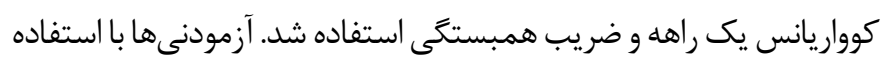

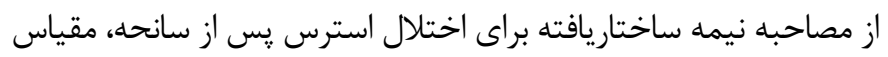

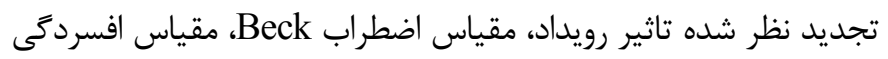

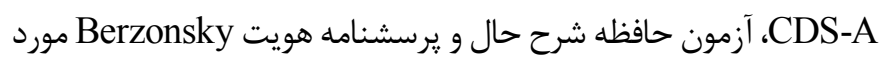

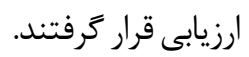

شده، افزايش در سطح انگيختگى و كرختى هيجانى (1). قرار كرفتن در

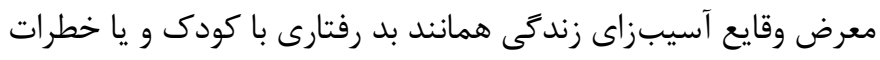

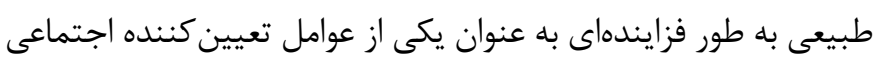

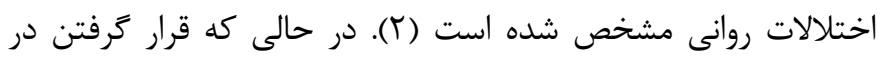

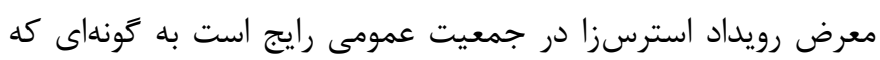

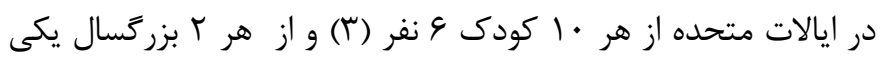

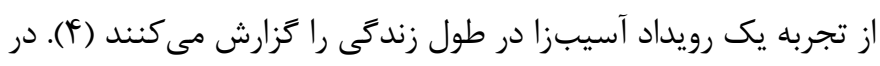

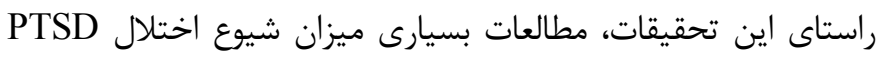

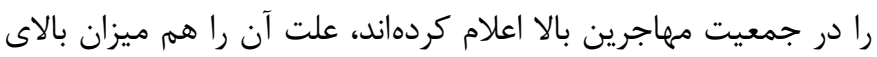

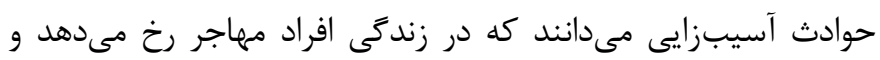

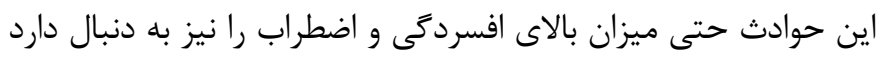

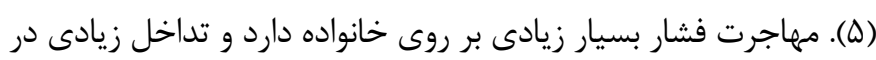

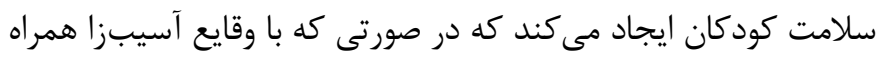

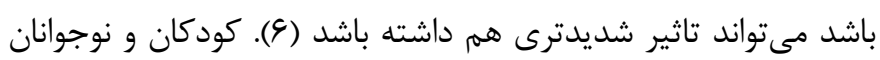

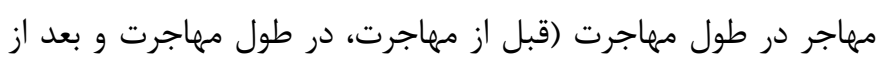

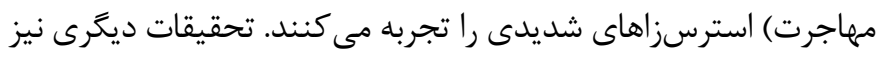

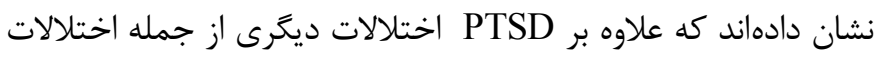

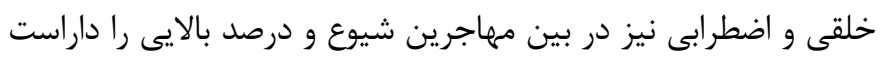

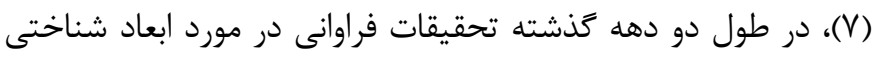

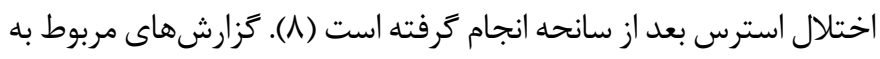

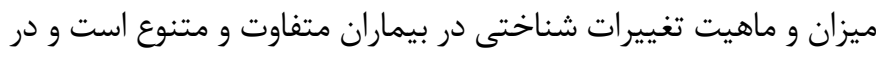

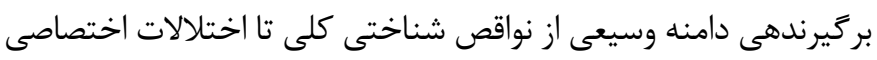

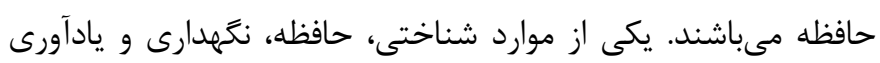

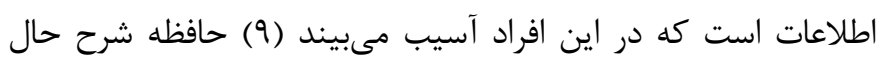
جنبهاى از حافظه است كه با يادآورى (Autobiographical memory)

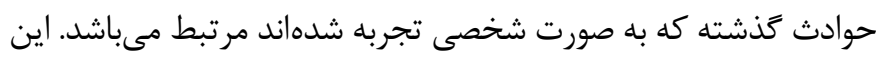
نوع حافظه دريجهاي به درون عملكرد هيجانى و انكيزشى فرد باز مى كند دها

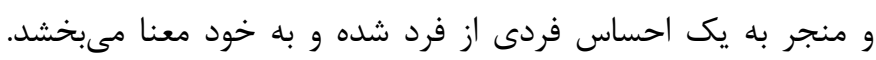

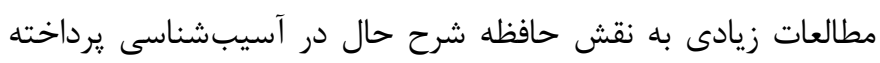

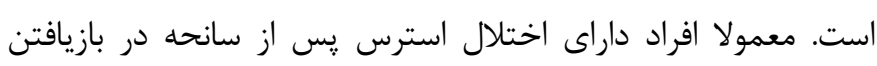

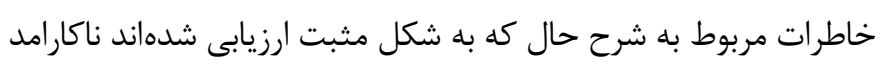

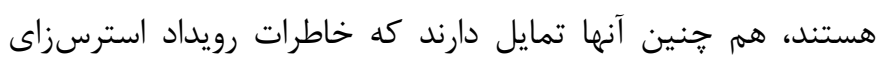

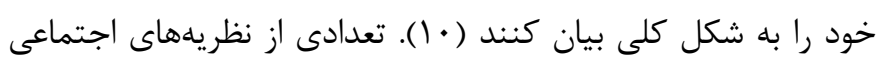

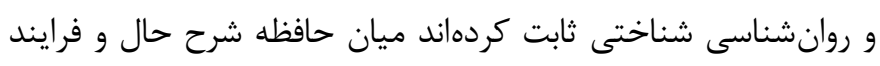

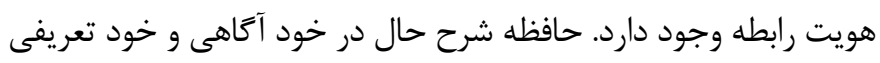

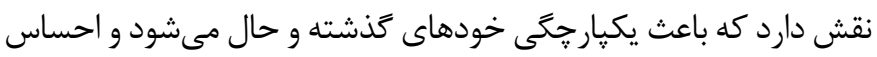

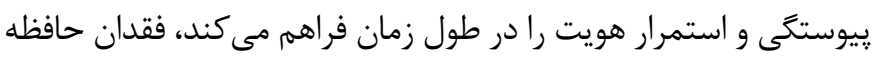




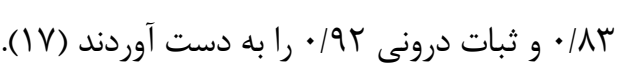

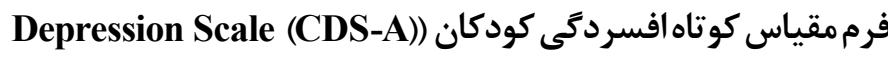

(Children

مقياس افسردگى كودكان (CDS) براى سنجش علايم افسردگى در

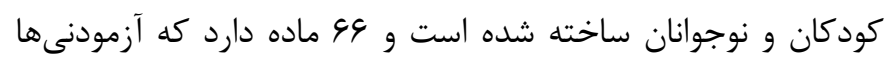

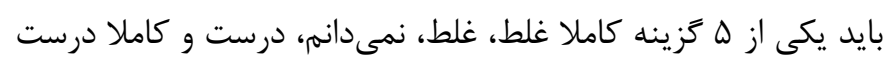

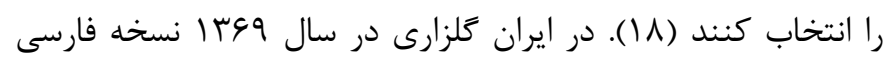

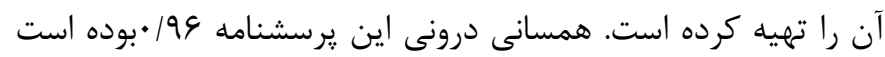

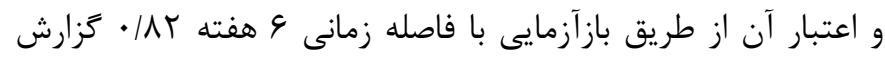

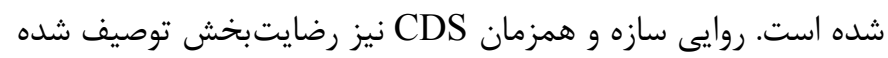

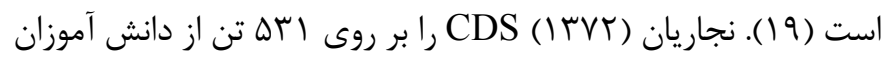

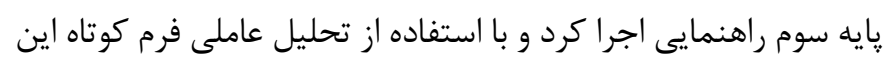

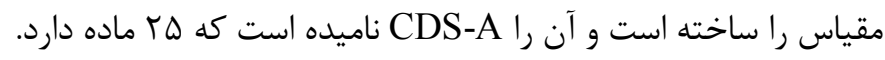

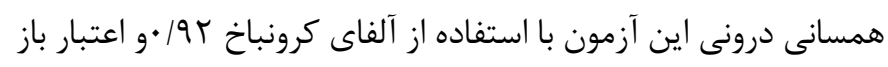

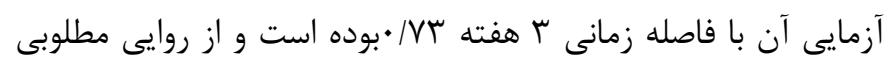

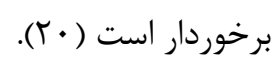

آزمون حافظه شرح حال (Autobiographical Memory Test (AMT) بحردار )

آزمون حافظه شرح حال كه اولين بار Williams و Broadbent آن

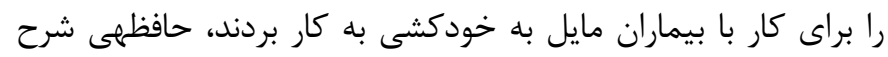

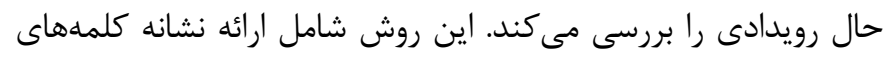

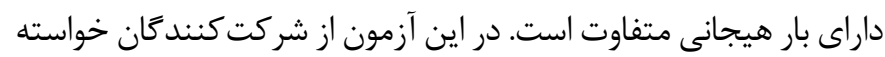

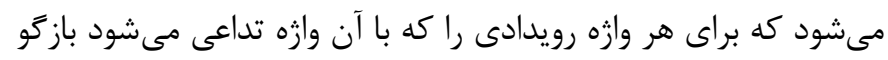

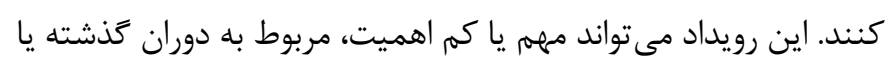

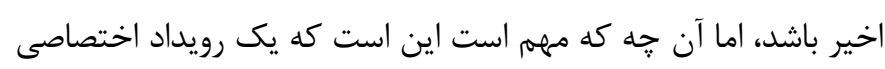

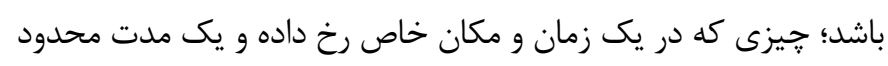

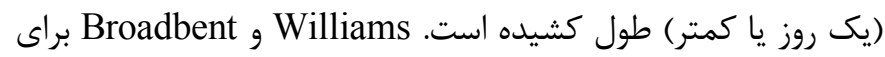
ياسخ به هر كلمه يك دقيقه به شركت كنند

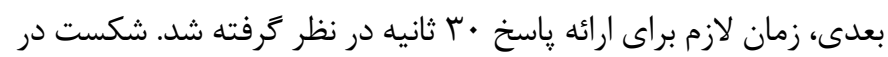

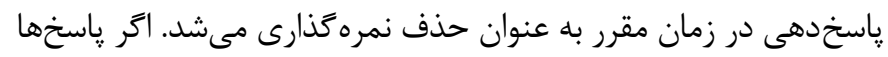

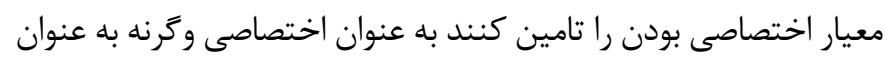

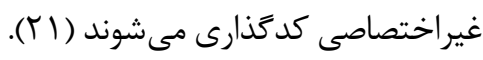

يرسشنامه سبكهاى هويت (Identity Style Inventory (ISI))

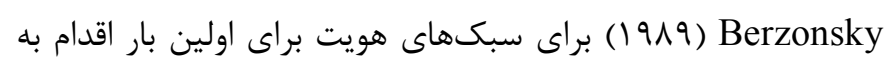

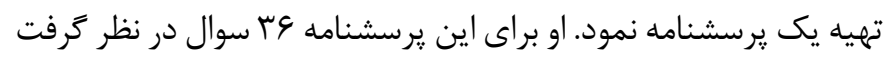

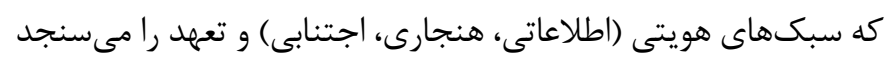

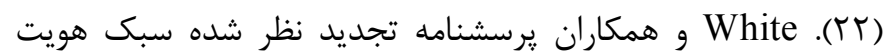

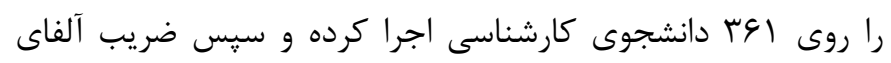

for DSM Axis I Disorders (SCID-I)) مصاحبهنيمهساختاريافته

(Structured Clinical Interview

مصاحبهاى است نيمه ساختار يافته كه بر اساس DSM-IV، تشخيصهايى

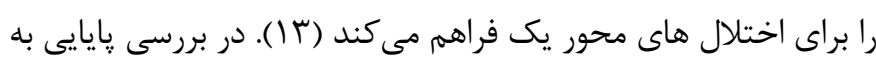

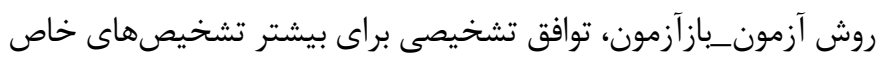

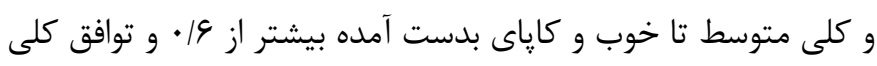

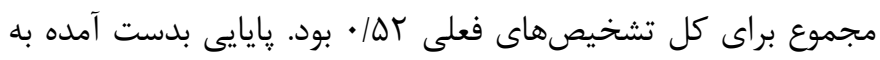

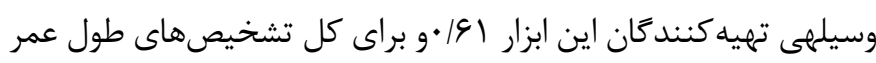

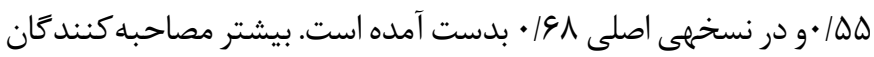

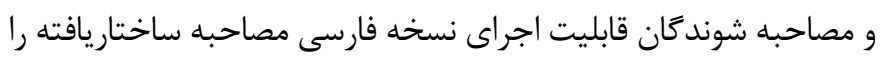
مطلوب كزارش كردند (4 (l).

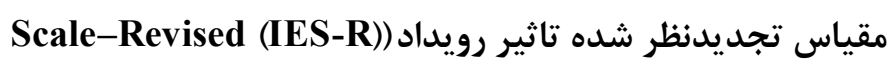

(The Impact of Event

اين مقياس را Meiess و Marmer در سال 199V، هماهنگ با ملاكهاى DSM-IV و براى تشخيص اختلال استرس يس از سانحه

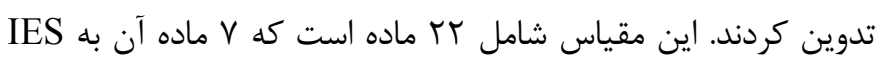

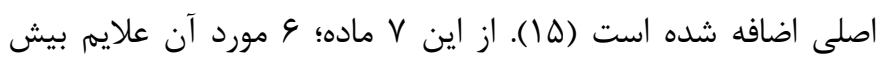

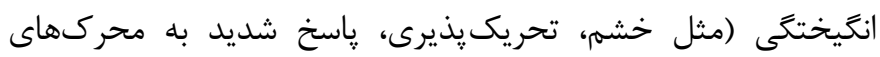

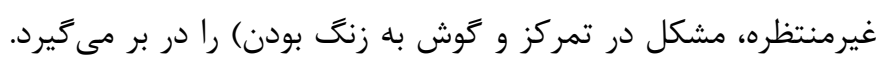

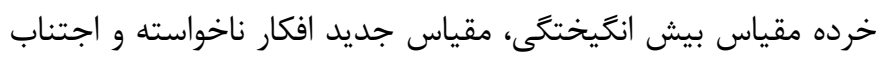

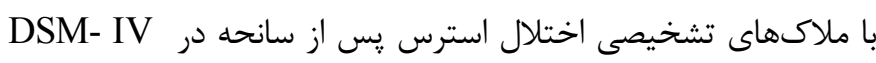

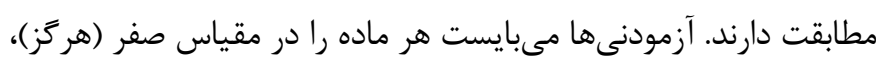

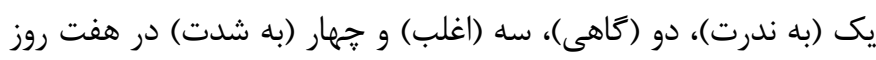

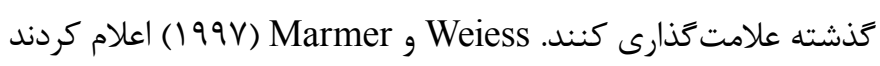

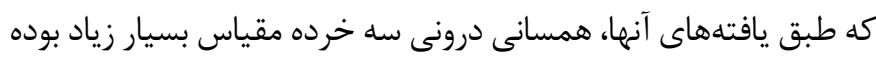

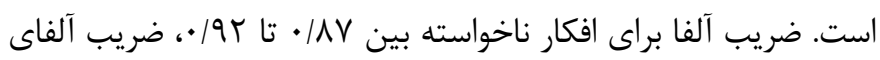

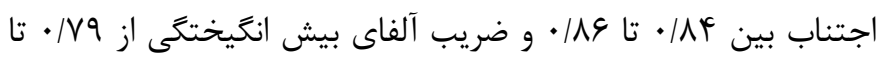

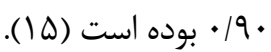

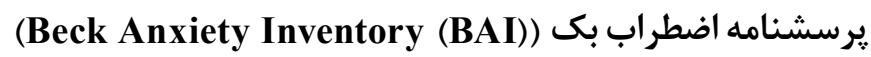

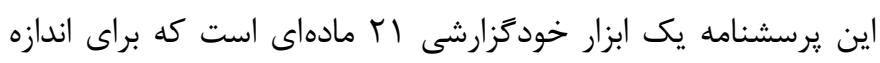

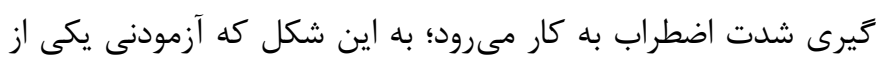

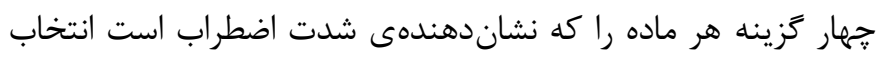

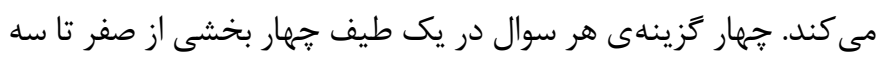

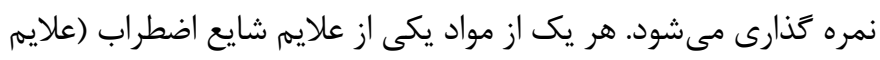

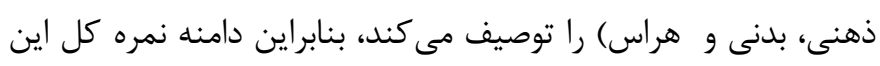

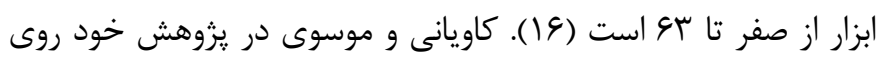

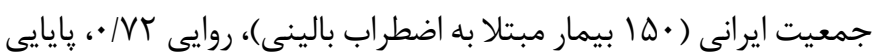


كرونباخ آن را محاسبه نمودند. اين ضريب براى سبك هويت اطلاعاتى يافته ها ميانخين و انحراف معيار سن گروه

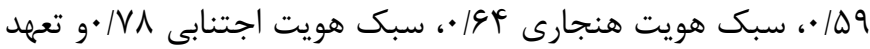
9 94/V9 • بدست آمد. آنان براى بررسى روايى همزمان، همبستكى هاى بين

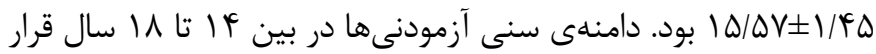
نسخه اصلى با نسخه تجديد نظر شده را محاسبه نمودند و همبستخى ريى رئى دارد كه از اين ميان آزمودنىهاى ها ساله بيشترين فراوانى را داشتند.

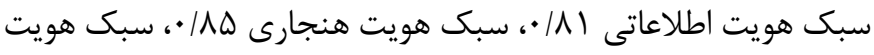

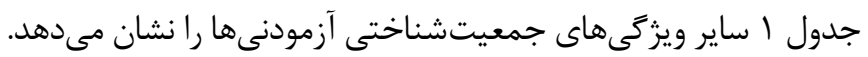

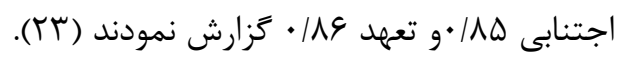

جدول ا. ويزگى جمعيتشناختى آزمودنى ها

\begin{tabular}{|c|c|c|c|c|}
\hline گروه مواجهه با آسيب & تروه PTSD & عروه سالم & \multicolumn{2}{|c|}{ متغيرها } \\
\hline if & 19 & 11 & \multicolumn{2}{|c|}{ تعداد آزمودنىها } \\
\hline$(F T / Q) \&$ & $(\Delta \cdot) \wedge$ & $(Y V / \Lambda) \Delta$ & دختر & \multirow{2}{*}{ 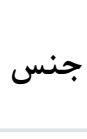 } \\
\hline$(\Delta V / I) \wedge$ & $(\Delta \cdot) \wedge$ & $(V T / T) \| r$ & يسر & \\
\hline$g / V \mid$ & V/IT & V/FY & \multicolumn{2}{|c|}{ تحصيل (ميانگين: سال) } \\
\hline
\end{tabular}

جدول ب نتايج تحليل واريانس عملكرد حافظه شرح حال را در گروههاى روهى از آزمون تعقيبى توكى استفاده شد. همانكًنه كه جدول r نشان مى بهد عملكرد گروه PTSD در حافظه مورد مطالعه نشان مى دهد. همانطور كه جدول فوق نشان مىدهد شرح حال از هر دو گروه كمتر و گروه بدون علايم اختلال نيز از گروه گروههاى مورد مطالعه در عملكرد حافظه شرح حال با يكديگر تفاوت كنترل يايينتر است كه در سطح معنادارى قرار دارند.

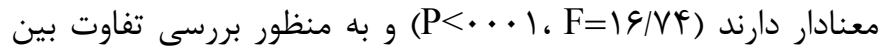

جدول r. تحليل واريانس حافظه شرح حال

\begin{tabular}{|c|c|c|c|c|c|}
\hline $\mathrm{P}$ & $\mathrm{F}$ & ميانگين مجذورات & درجه آزادى & مجموع مجذورات & منبع واريانس \\
\hline \multirow[t]{3}{*}{$\cdot|\cdots|$} & IS/VF & FN/FT & r & $१ ९ / \wedge \Delta$ & كروه \\
\hline & & r/^ & Fa & $\| r \cdot / 1 f$ & خطا \\
\hline & & & FV & trt/. & 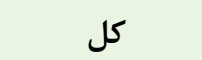 \\
\hline
\end{tabular}

جدول r. آزمون تعقيبى توكى براى حافظه شرح حال

\begin{tabular}{|c|c|c|c|c|}
\hline $\mathrm{P}$ & خطاى استاندارد & تفاوت ميانكَينها & تروهها & تروهها \\
\hline$\cdot / \cdot r$ & $\cdot 194$ & $-1 / \Delta \Lambda$ & مواجهه با آسيب & \multirow{2}{*}{ PTSD } \\
\hline $.1 . .1$ & $\cdot \mid \Delta \Lambda$ & -rr/ & كنترل & \\
\hline$\cdot / \cdot r$ & .194 & $1 / \Delta \Lambda$ & PTSD & \multirow{2}{*}{ مواجهه با آسيب } \\
\hline$\cdot / \cdot 1$ & $\cdot 19$ & $-1 / 29$ & كنترل & \\
\hline$\cdot \mid \cdot \cdot 1$ & $\cdot \mid \Delta \Lambda$ & 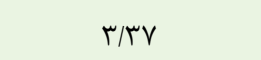 & PTSD & \multirow{2}{*}{ كنترل } \\
\hline $.1 \cdot 1$ & $\cdot 19$ & $1 / 79$ & مواجهه با آسيب & \\
\hline
\end{tabular}


متغير افسردگى نيز گروه PTSD به طور قابل توجه بالاتر از دو گروه ديخر است. به همين دليل به منظور بررسى عملكرد حافظه شرح حال در گروهها، اين دو متغير به عنوان متغير كنترل وارد تحليل شدند. همانطور كه جدول f أشان مىدهد مقادير F بدست آمده براى متغيرهاى اضطراب و افسردگى معنادار نبود، اما عملكرد حافظه شرح حال

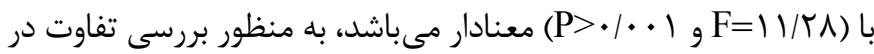
بين گروهها از آزمون تعقيبى توكى استفاده شد كه نتايج آن در جدول

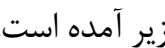

با توجه به اينكه به لحاظ مفهومى اضطراب و افسردگى دو متغير موثر در اختلال PTSD هستند، در اين يزوهش اين متغيرها نيز مورد بررسى قرار كرفت، نتايج بدست آمده حاصل از مقايسه ميانخَين هاى اين دو نشاندهنده

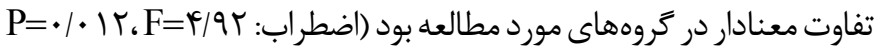

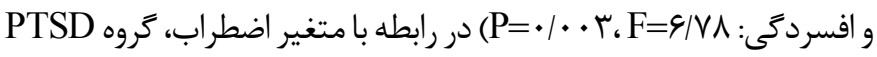
نسبت به هر دو گروه ديگر نمرات بالاتر و معنادارى داشته و گروه بدون علايم اختلال استرس يس از سانحه نيز در ميانگين نسبت به كروه كنترل بالاتر بوده كه با توجه به ماهيت ضربه و آسيب اين امر قابل توجيه است. در

جدول f. تحليل كوواريانس با كنترل اضطراب و افسردىى بر حافظهشرححال در سه كروه

\begin{tabular}{|c|c|c|c|c|c|}
\hline $\mathrm{P}$ & $\mathrm{F}$ & ميانگين مجذورات & درجه ازادى & مجموع مجذورات & منبع واريانس \\
\hline$\cdot / V^{F}$ & .11 & $\cdot \pi \cdot$ & 1 & $\cdot / r$. & اضطراب \\
\hline$\cdot / T V$ & $1 / T$ & $r|\Delta|$ & 1 & $r|\Delta|$ & افسردَى \\
\hline \multirow[t]{3}{*}{$\cdot|\cdots|$} & $11 / r \Lambda$ & r & r & sq1.r & كروه \\
\hline & & T/QT & kr & ITQ/AT & خطا \\
\hline & & & FV & trV & كل \\
\hline
\end{tabular}

مى باشند و با توجه به اينكه گَروه بدون علايم اختلال نيز به علت رويداد آسيبزايى كه تجربه كردهاند از اضطراب و افسردگى برخوردارند، مى توان كفت كه اين عوامل باعث كاهش تفاوت شدهاند.
همانگونه كه جدول ه فوق نشان مىدهد تفاوت بين دو گروه PTSD و گروه بدون علايم اختلال معنادار نبود (9= (P=). از آنجايى كه از عوامل موثر بر روى كاركردهاى اجرايى و حافظه، اضطراب و افسردگى بدى

$$
\text { جدول ه. آزمون تعقيبى توكى براى حافظهشرح حال با كنترل اضطراب و افسردىى }
$$

\begin{tabular}{|c|c|c|c|c|}
\hline $\mathrm{P}$ & خطاى استاندارد & تفاوت ميانگين ها & \multicolumn{2}{|c|}{ تروهها } \\
\hline$\cdot 1 \cdot 9$ & $\cdot 199$ & $-1 / T$ & مواجهه با آسيب & \multirow{2}{*}{ PTSD } \\
\hline$\cdot|\cdots|$ & $\cdot 199$ & $-r / \cdot V$ & كنترل & \\
\hline$\cdot 1 \cdot 9$ & .199 & $1 / \pi$ & PTSD & \multirow{2}{*}{ مواجهه بآسيب } \\
\hline $.1 . .9$ & $\cdot \mid q 4$ & $-1 / 1 \mathrm{~V}$ & كنترل & \\
\hline$\cdot|\cdots|$ & $\cdot 199$ & $r / \cdot \vee$ & PTSD & \multirow{2}{*}{ كنترل } \\
\hline .1 .94 & .194 & $1 / \lambda V$ & مواجهه با آسيب & \\
\hline
\end{tabular}

بحث در گروهها از تحليل واريانس جندمتغيره استفاده شد.

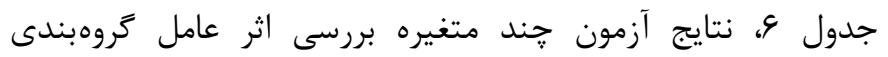

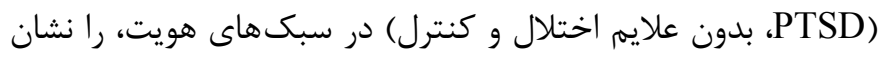

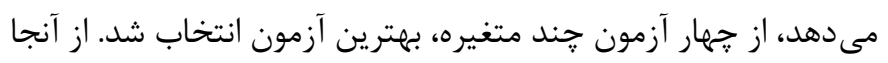

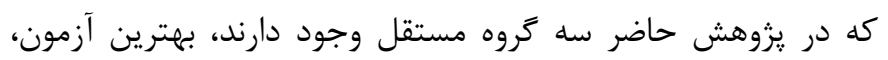

به منظور بررسى رابطه بين عملكرد حافظه شرح حال با سبكهاى

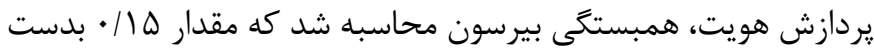

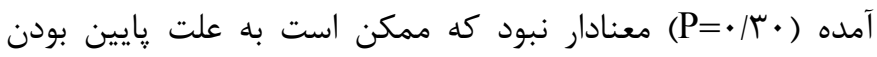

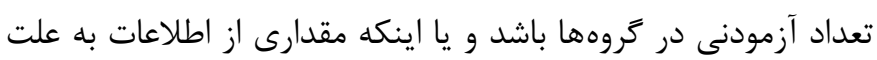

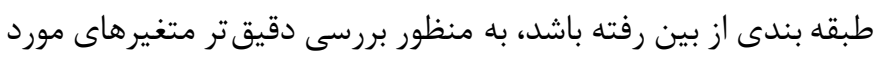


هويت بر اساس آزمون تعقيبى نشاندهنده اين بود كه ميانخين نمرات سبك يردازش اطلاعاتى در افراد بدون علايم اختلال استرس يس إز لهاز

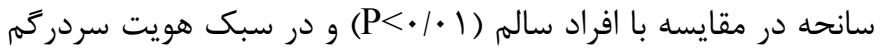
ميانگَين نمرات گروه PTSD در مقايسه با افراد بدون علايم اختلال

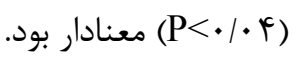

لامبداى ويلكز بود، همانطور كه نتايج نشان مى دهد كه اثر كلى عامل كروهبندى در متغير وابسته سبك هاى هويت معنادار است (ب •/ P= (P). همانكَونه كه جدول V نشان مى دهد تنها در سبك يردازش هويت

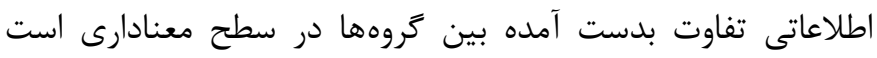

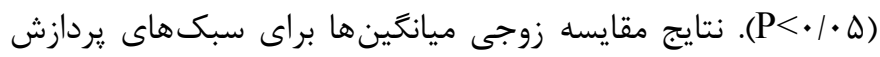

جدول \&. نتايج آزمون هاى جند متغيرى

\begin{tabular}{|c|c|c|c|c|c|c|}
\hline $\mathrm{P}$ & درجه آزادى خطا & درجه آزادى مفروض & $\mathrm{F}$ & ارزش & متغير ها & منابع تغييرات \\
\hline.$/ . r$ & $\Lambda$ & 9 & T/AT & $\cdot / r \Lambda$ & اثر بيلايى & \multirow{4}{*}{ كروه } \\
\hline$\cdot / \cdot r$ & $\wedge \varepsilon$ & 4 & $r / F$ & $\cdot / v r$ & لانداى ويلكز & \\
\hline . & $\Delta F$ & 4 & $r / r \Lambda$ &.$\mu F$ & اثر هتلينگ & \\
\hline.$/ . r$ & fr & r & $r / 9$. & $\cdot \pi F$ & بزركترين ريشه روى & \\
\hline
\end{tabular}

جدول צ. نتايج آزمون هاى جند متغيرى

\begin{tabular}{|c|c|c|c|c|c|}
\hline $\mathrm{P}$ & $\mathrm{F}$ & ميانغين مجذورات & درجه آزادى & مجموع مجذورات & منبع واريانس \\
\hline.$/ . r$ & $r / 91$ & $|r \Delta| \cdot q$ & $r \Delta \cdot / 19$ & سبك اطلاعاتى & \multirow{3}{*}{ كروه } \\
\hline سז/. & 1 & $r V / r Y$ & $\Delta F / G \Lambda$ & سبك هنجارى & \\
\hline \multirow[t]{7}{*}{$\cdot / \pi$} & r/lF & $91 / 4 V$ & $\mid r T / Q F$ & سبك سردرَمم & \\
\hline & & $r / 91$ & $\mid<r q / 10$ & سبك اطلاعاتى & \multirow{3}{*}{ خطا } \\
\hline & & $T F / F V$ & $11 \cdot 1 / r \Lambda$ & سبك هنجارى & \\
\hline & & YN/GV & $\mid r q \cdot / 4 r$ & سبك سردر كم & \\
\hline & & & $1919 / \pi \Delta$ & سبك اطلاعاتى & \multirow{3}{*}{ 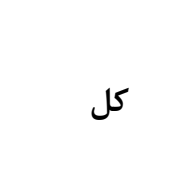 } \\
\hline & & & $11 \Delta \Delta / 9 V$ & سبك هنجارى & \\
\hline & & & $|F| r / T V$ & سبك سردرگم & \\
\hline
\end{tabular}

كه اين در راستاى ساير يزوهشهاى انجام شده در اين حوزه مىباشد،

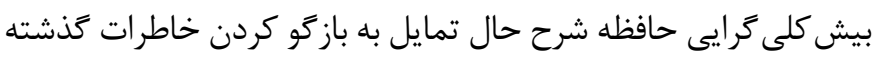

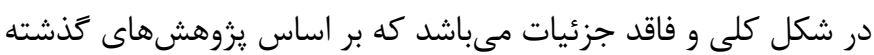
نه فقط خاطرات مرتبط با رويداد استرسزا بلكه همه خاطرات را شامل مىشود (YF). در مورد اين نقص دو تبيين وجود دارد، اولين فرضيه تعديل اثر، بيان مى كند كه كاهش اختصاصى بودن حافظه، بيانكر يك راهبرد شناختى براى ممانعت از دسترسى به جزئيات حوادث شرح

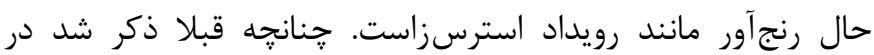
زندگى مهاجرين حوادث استرسزا و آسيبزاى بسيارى اتفاق مى مافتد
در يزوهش حاضر عملكرد حافظه شرح حال و سبكهاى يردازش هويت

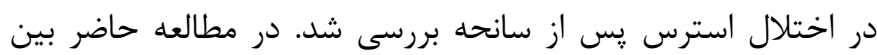

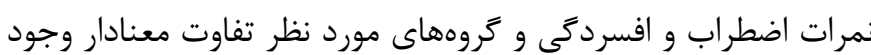
داشت. در تبيين اين مساله Nickerson و همكاران (II (Y) معتقدند به دليل وجود حوادث آسيبزاى بسيار در زندكى روزمره افراد مهاجر شيوع اختلالهاى افسردىى و اضطراب در اين جمعيت بسيار بالا بوده است (V). همجٍنين نتايج نشان داد كه حافظه شرح حال در نوجوانان مهاجر افغان مبتلا به PTSD نسبت به كروه سالم و كروه بدون علايم اختلال استرس يس از سانحه از اختصاصى بودن كمترى برخوردار بود 
شرح حال و سبكهاى هويت رابطهى معنادارى ديده نشد. در ديدگاه افراد از اواخر كودكى و دوره نوجوانى شروع به استفاده از McAdams خاطرات شرح حال براى شكل دادن هويت خود مى كنند (9 ؟)، با توجه

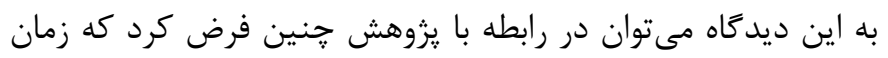

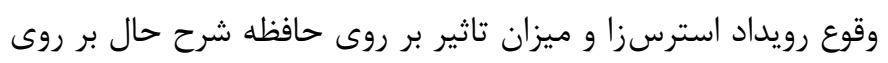

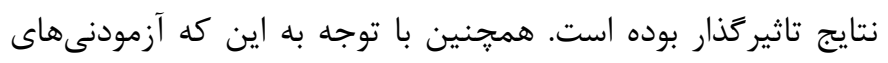

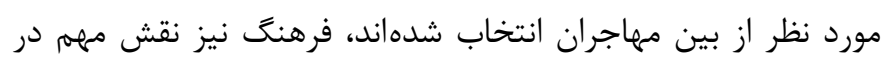

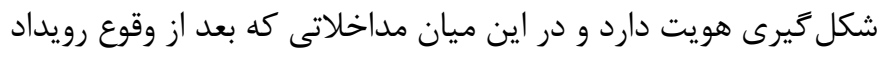

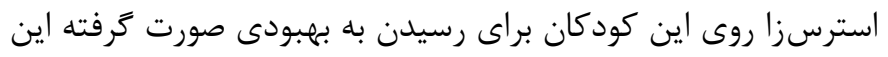
اثر را تعديل كرده است. از طرفى متغير هويت با عامل سن بيوند زيادى لئى

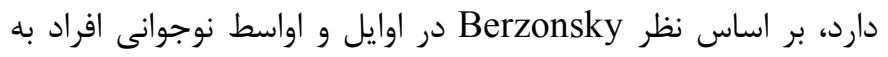

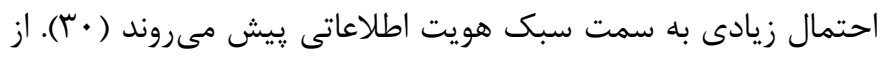

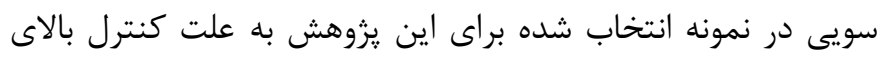

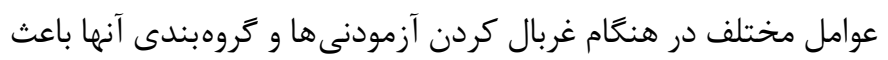

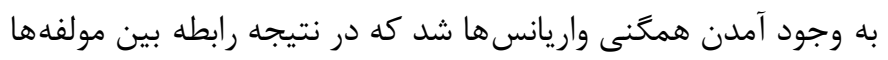
معنادار نشد.

\section{نتيجه كيرى}

يافتهاى يزوهش حاضر نشان داد كه عملكرد نوجوانان مهاجر مبتلا

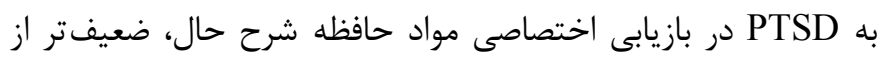

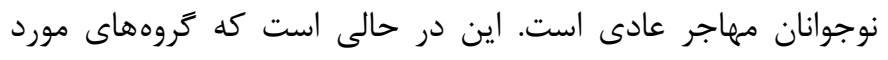

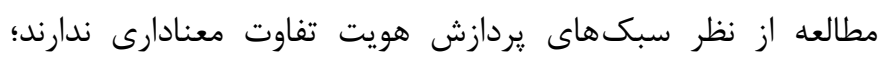

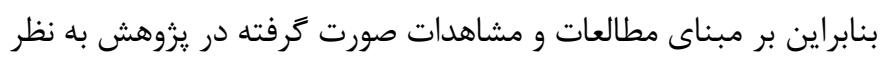

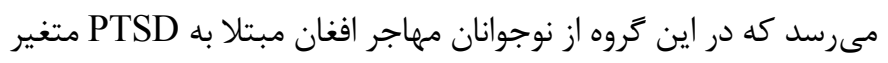
حافظه شرح حال نقش واسطه اي در تبيين سبكهاى هويتى ندارد.

\section{تشكر و قدردانى}

يزوهش حاضر برَرفته از پايان نامه كارشناسى ارشد نويسنده نخست

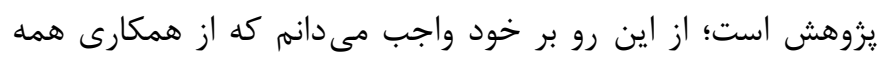

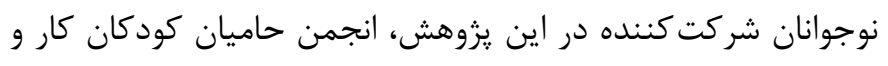

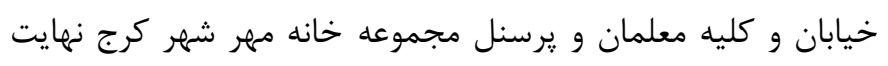
سر:اس و قدردانى را داشته باشم.
كه نوجوانان مهاجر افغان مبتلا به PTSD با استفاده از يك راهبرد

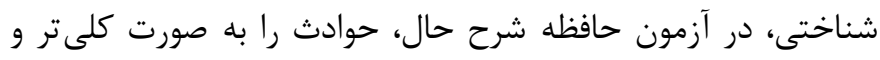

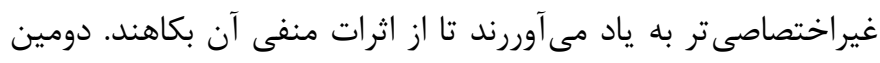

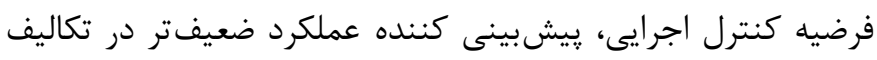

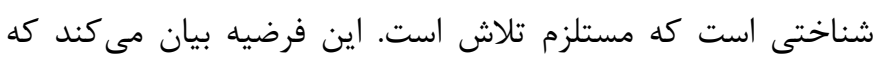
كاهش يافتخى اختصاصى بودن حافظه، به عنوان نمونهاى إن از عملكرد ضعيف در تكاليف شناختى، ناشى از كنترل اجرايى تقليل يافته است.

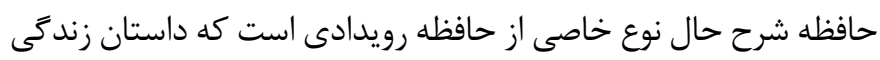

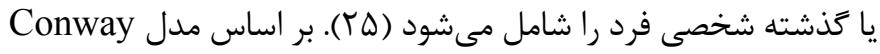
(ه • (T) حافظه رويدادى سيستم حافظهاى است كه اطلاعات مرتبط با فعاليتهاى مرتبط با هدف اخير را ضبط مى كند كه با اهداف كوافئ كوتاه

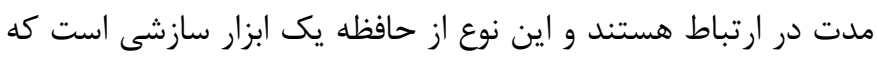

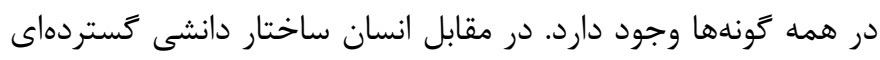

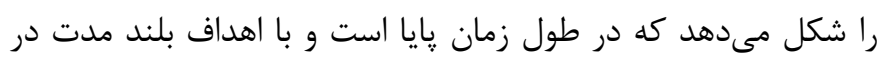

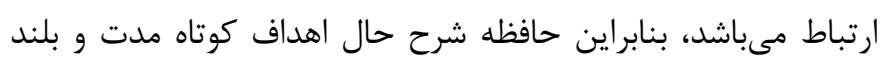

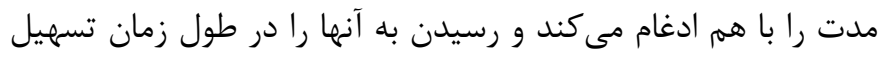

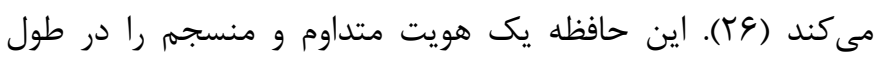

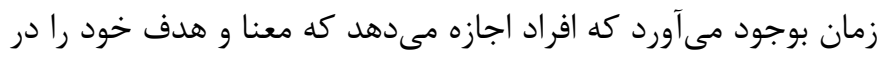

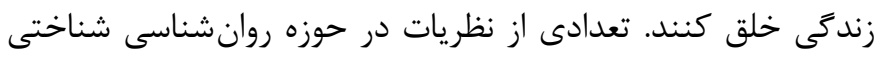

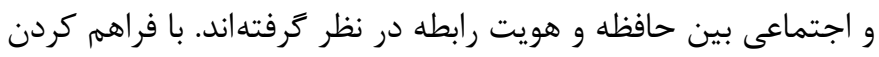

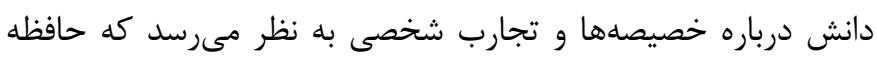

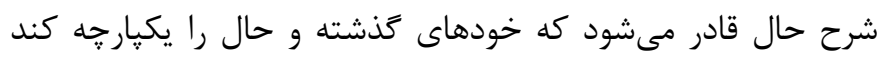

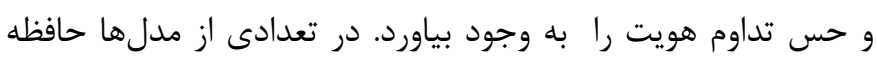

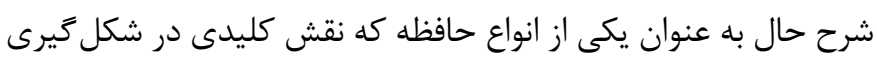

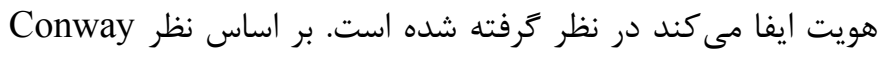

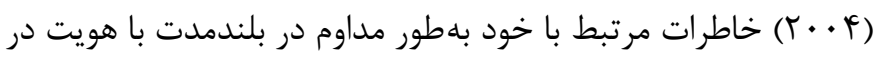

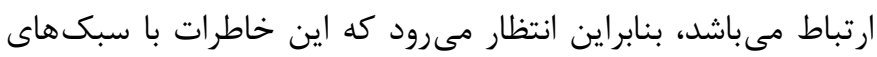

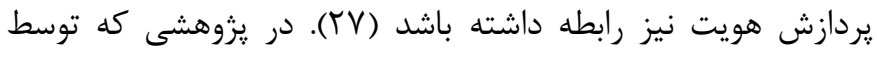

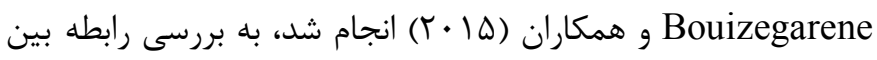

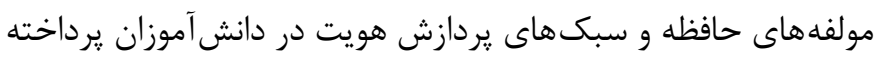

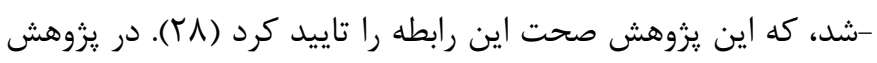

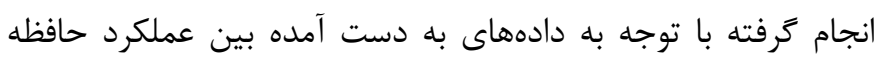




\section{References}

1. American Psychiatric Association. Diagnostic and statistical manual of mental disorders (DSM-5®):Arlington:American Psychiatric Pub;2013.

2. McLaughlin KA, Green JG, Gruber MJ, Sampson NA, Zaslavsky AM, Kessler RC. Childhood adversities and adult psychiatric disorders in the national comorbidity survey replication II: Associations with persistence of DSM-IV disorders. Archives of General Psychiatry. 2010;67(2):124-132.

3. McLaughlin KA, Koenen KC, Hill ED, Petukhova M, Sampson NA, Zaslavsky AM, et al. Trauma exposure and posttraumatic stress disorder in a national sample of adolescents. Journal of the American Academy of Child \& Adolescent Psychiatry. 2013;52(8):815-830.

4. Kessler RC, Sonnega A, Bromet E, Hughes M, Nelson CB. Posttraumatic stress disorder in the national comorbidity survey. Archives of General Psychiatry. 1995;52(12):1048-1060.

5. Momartin S, Silove D, Manicavasagar V, Steel Z. Comorbidity of PTSD and depression: Associations with trauma exposure, symptom severity and functional impairment in Bosnian refugeesresettled in Australia. Journal of Affective Disorders. 2004;80(2):231-238.

6. Wiese EB-P. Culture and migration: Psychological trauma in children and adolescents. Traumatology. 2010;16(4):142-152. 7. Nickerson A, Bryant RA, Silove D, Steel Z. A critical review of psychological treatments of posttraumatic stress disorder in refugees. Clinical Psychology Review. 2011;31(3):399-417.

8. Dalgleish T. Cognitive approaches to posttraumatic stress disorder: The evolution of multirepresentational theorizing. Psychological Bulletin. 2004;130(2):228-260.

9. Williams JMG, Barnhofer T, Crane C, Herman D, Raes F, Watkins E, et al. Autobiographical memory specificity and emotional disorder. Psychological Bulletin. 2007;133(1):122-148

10. Sutherland K, Bryant RA. Autobiographical memory and the self-memory system in posttraumatic stress disorder. Journal of Anxiety Disorders. 2008;22(3):555-560.

11. Rose Addis D, Tippett L. Memory of myself: Autobi- ographical memory and identity in Alzheimer's disease. Memory. 2004;12(1):56-74.

12. Conway MA, Pleydell-Pearce CW. The construction of autobiographical memories in the self-memory system. Psychological Review. 2000;107(2):261-288.

13. American Psychiatric Association. Diagnostic criteria from DSM-IV-TR. Washington, DC:American Psychiatric Publication; 2000

14. Sharifi V, Asadi SM, Mohammadi MR, Amini H, Kaviani H, Semnani Y, et al. Reliability and feasibility of the Persian version of the structured diagnostic interview for DSM-IV (SCID). Advances in Cognitive Sciences. 2004;6(1-2):10-22. (Persian)

15. Weiss DS, Marmar CR. The impact of event scale-revised. In: Wilson JP, Keane TM, editors. Assessing psychological trauma and PTSD. New York:Guilford Press;1997. pp. 399-411.

16. Beck AT, Epstein N, Brown G, Steer RA. An inventory for measuring clinical anxiety: Psychometric properties. Journal of Consulting and Clinical Psychology. 1988;56(6),863-897.

17. Kaviani H, Mosavi A. Psychometric properties of the Persian version of Beck Anxiety Inventory (BAI). Tehran University Medical Journal. 2008;66(2):136-140. (Persian)

18. Lang M, Tisher M. Childrens Depression Dcale: Second research edition. Melbourne:The Australin Council for Educational Research Limited;1983.

19. Golzari M. The construction and validation of the children's depression scale [MA Thesis]. Tehran:Iran University of Medical Sciences;1990. (Persian)

20. Najarian B. The construction and validation of the short form of Children's Depression Scale (CDS-A) by factor analysis. Psychological Research. 1994;2(3-4):24-44. (Persian)

21. Williams JM, Broadbent K. Autobiographical memory in suicide attempters. Journal of Abnormal Psychology. 1986;95(2):144-149.

22. Berzonsky MD. Identity style: Conceptualization and measurement. Journal of Adolescent Research. 1989;4(3):268-282. 23. White JM, Wampler RS, Winn KI. The Identity Style In- 
ventory: A revision with a sixth-grade reading level. Journal of Adolescent Research. 1998;13(2):223-245.

24. Ahadi M, Moradi A, Hasani J. The study of autobiographical memory in immigrant adolescents suffering from post-traumatic stress disorder (PTSD). Thoughts and Behavior in Clinical Psychology. 2015;9(34):77-86. (Persian)

25. Fivush R, Habermas T, Waters TE, Zaman W. The making of autobiographical memory: Intersections of culture, narratives and identity. International Journal of Psychology. 2011;46(5):321-345.

26. Conway MA. Memory and the self. Journal of Memory and Language. 2005;53(4):594-628.

27. Conway MA, Singer JA, Tagini A. The self and autobi- ographical memory: Correspondence and coherence. Social Cognition. 2004;22 (5: Special issue):491-529.

28. Bouizegarene N, Philippe FL. Episodic memories as building blocks of identity processing styles and life domains satisfaction: Examining need satisfaction and need for cognitive closure in memories. Memory. 2016;24(5):616-628.

29. McAdams DP, Pals JL. A new Big Five: Fundamental principles for an integrative science of personality. American Psychologist. 2006;61(3):204-217.

30. Berzonsky MD, Ferrari JR. A diffuse-avoidant identity processing style: Strategic avoidance or self-confusion?. Identity: An International Journal of Theory and Research. 2009;9(2):145-158. 